\title{
Biological control of pastoral pests using Acremonium spp. endophytes
}

\author{
R.A. PRESTIDGE, A.J. POPAY and O.J-P. BALL \\ AgResearch, Ruakura Agricultural Research Centre, Private Bag 3123, Hamilton
}

\begin{abstract}
Although the role of the endophytic fungus Acremonium lolii in protecting the host plant from attack by insect pests, particularly Argentine stem weevil (Listronotus bonariensis), is often described in terms of plant resistance, it is a case of classical biological control. Endophytes in commercially available perennial ryegrass cultivars are acting as biological control agents against at least four pest species in New Zealand. Generally, endophyte adversely affects insect stages that feed on the above-ground parts of the plant, particularly those stages that feed near the base of the plant. It is apparent from insect feeding tests that there is no one universal anti-insect metabolite that will adversely affect all pest populations. It is therefore likely that an endophyte/grass combination that produces a cocktail of metabolites at low concentrations may be more useful than a combination that produces a very narrow suite of metabolites.
\end{abstract}

Keywords: Acremonium spp., Listronotus bonariensis, Heteronychus arator, Costelytra zealandica, Wiseana spp., biological control, endophyte

\section{Introduction}

The majority of perennial ryegrass plants (Lolium perenne L.) in pastures that are more than 2-3 years old in New Zealand are infected with the endophytic fungus Acremonizun lolii Latch, Christensen \& Samuels. A. lolii-infected ryegrasses are usually at a selective advantage over endophyte-free counterparts and, as a result, the incidence of endophyte infection in a pasture increases from the time of sowing to equilibrate near 95- 100\%. The major reason for this selective advantage is that the endophyte protects the host ryegrass plant from attack by plant-feeding insects. This defence has been utilised commercially by various seed companies who produce and market endophyte-infected perennial ryegrass seed to those areas of New Zealand where pasture pests such as Argentine stem weevil (Listronotus bonariensis (Kuschel)) are a significant economic problem. Thus, the endophyte is a fungus that is acting as a biological control agent to protect the host grass (and itself) from pest attack.

A biological control agent can be defined as an organism that acts to reduce the impact and resilience of a pest or weed (Goldson \& Phillips 1993). In classical biological control, controlling agents are usually chosen from the region of origin of the pest or weed. This improves the probability of successful establishment of an imported biological control agent as the pest and biological control agent have usually co-evolved. However, this is not the case with Acremonium spp. and Argentine stem weevil as the endophytic fungus probably originated from Europe whereas Argentine stem weevil originated from South America. In its native habitat, Argentine stem weevil would probably not have come into contact with Acremonium spp. without the intervention of man as it feeds on unimproved Poa spp. and Bromus spp.

The potential of endophytic fungi as biological control agents was first realised in March 1982 with the first observation of an endophyte conferred resistance to ryegrass from insects (Prestidge et al. 1982). Research into the mechanisms of these relationships has been largely confined to the effects of A. lolii in perennial ryegrass on Argentine stem weevil. Much of this work has been recently reviewed (Prestidge \& Ball 1993) and avid followers of endophyte/grass interactions are referred-to-the-review--papers edited by Hume et al. (1993).

\section{Effects of endophytic fungi on pasture pests}

In New Zealand, endophytes in commercially available perennial ryegrass cultivars are already acting as biological control agents against four insect species (Table 1). In addition to these four species, sod webworm (Crambus spp.) (Funket al. 1983) and black field cricket (Teleogryllus commodus Walker) (Van Heeswijck and McDonald 1992) may also be adversely affected by endophyte, although this has yet to be confirmed for the New Zealand populations. In all of these cases of endophyte-conferred resistance, endophyte infection adversely affects the insect stages that feed on the aboveground parts of plants, particularly those stages that feed near the base of the plant where thk concentrations of endophyte mycelium and most of the known alkaloids are greatest. We have been unable to demonstrate any 
major adverse effect on the plant root feeding stages of susceptible insects such as black beetle or on other root feeding invertebrates with the possible exception of Paratylenchus sp., a plant parasitic nematode (Prestidge et al. 1993). This is in spite of the detection of mycelium and associated alkaloids in the roots of endophyteinfected plants.

Table 1 New Zealand insects adversely affected by A.loliiinfected perennial ryegrass.

\begin{tabular}{lll}
\hline Common name & Scientific name & Reference \\
\hline $\begin{array}{l}\text { Argentine } \\
\text { stem weevil }\end{array}$ & Listronotus bonariensis & Prestidge et al. 1982 \\
$\begin{array}{l}\text { Pasture } \\
\text { mealybug }\end{array}$ & Baianococcuspoae & Pearson 1989 \\
$\begin{array}{l}\text { Cutworm } \\
\text { Black beetle }\end{array}$ & $\begin{array}{l}\text { Graphania mutans } \\
\text { Heteronychus arator }\end{array}$ & Dymock et al. 1989 \\
\hline
\end{tabular}

Most of the research on insect-endophyte interactions has been done on Argentine stem weevil, a major pest of grasses and cereals throughout most of New Zealand. Adult Argentine stem weevil use a large number of olfactory and gustatory senses to detect the presence of endophyte in perennial ryegrass which usually deters them. Females will also not usually lay eggs on endophyte-infected grasses because they detect the endophyte when they chew a small hole at the base of the grass tiller prior to inserting an egg. This behaviour is critical to the success of Argentine stem weevil as larvae hatch from eggs and immediately start to tunnel into the grass tillers. If eggs are not laid on infected plants, then the damaging larval stage is usually absent from these plants.

Endophyte also adversely effects Argentine stem weevil in other ways. For example, larvae that are present on endophyte-infected plants have lower survival (Barker et al. 1984b) and reduced growth rates than larvae present on endophyte-free plants (Prestidge \& Gallagher 1988). Adult Argentine stem weevil that are confined to endophyte-infected ryegrasses produce very few eggs (Barker et al. 1984a) and have increased flight muscle development (Barker et al. 1989) which will aid dispersal away from endophyte-infected plants.

Similarly with black beetle in northern New Zealand, the major effect of endophyte is on the adult stage which feeds at the base of grasses from autumn until late spring. Adult black beetle preferentially feed on endophyte-free rather than on endophyte-infected ryegrasses (Ball \& Prestidge 1992). As a result of this selective feeding, adults avoid laying eggs near endophyte-infected ryegrass and the damaging larval densities are consequently low (Prestidge et al. 1993).
Other insects which are affected by A. lolii include the pasture mealybug, (Balanococcus poae (Maskell)) and the cutworm (Graphania mutans (Walker)). Both insects are found throughout New Zealand but are not considered to be serious agricultural pests. The pasture mealybug feeds on crowns, roots and basal stem areas of improved grasses. Infection of perennial ryegrass by $A$. lolii reduced settlement of mealybug crawlers and improved ryegrass survival when infested by $\boldsymbol{B}$. poae (Pearson 1989). The caterpillars of G. mutans, which feed on a range of pasture species, had reduced feeding and slower growth rates when feeding on $A$. lo/ii-infected perennial ryegrass (Dymock et al. 1989). A number of other moth species with minor pest status are also present in New Zealand pastures. Some closely related species in Australia are adversely affected by A.lolii (Van Heeswijwk \& McDonald 1992).

The effects on grass grub larvae have also been investigated. Commercially available endophyteinfected ryegrass cultivars apparently do not have any adverse effect as population densities are similar on endophyte-infected and endophyte-free ryegrass based pastures. However, feeding trials carried out with various Acremonium spp. endophyte/fescue (Festuca arundinacea Schreb. and F. pratensis Huds.) combinations have indicated that many of these significantly reduced third instar grass grub survival and delayed larval growth over a 6 week period (Popay et al. 1993). Survival ranged between 12 and $65 \%$ of that in the endophyte-free comparison. Short term feeding tests have also shown that very young porina (Wiseana cervinata Walker) caterpillars (i.e. 2-4 weeks old) are sensitive to some endophyte/fescue and endophyte/ryegrass combinations (Popay, unpub. data).

\section{What are the alkaloids involved}

There has been a great deal of research conducted to identify and quantify the alkaloids produced by the endophyte and to measure the effects of these alkaloids on insect and animal performance. Much of this work is inherently difficult and is compounded in that often only very small quantities (parts per billion) of alkaloid can be detected. Three broad groups of alkaloids, the indole diterpenes (including the lolitrems and paxilline), peramine and the ergopeptines, are produced in commercially available ryegrass cultivars by the association of $A$. lolii and perennial ryegrass.

These alkaloids have been tested on insects by incorporating them into artificial diets in concentrations usually found in endophyte-infected ryegrass. Other tests offer the insect a choice between diet with and without alkaloids. Within the lolitrems, lolitrem B usually occurs in the greatest proportion and is primarily 
Table 2 The effect of some of the major metabolites produced by endophyte/ryegrass associations on five pastoral pest species in New Zealand $(t=$ adversely affected, $\bullet=$ no adverse affect, $n t=$ not tested $)$.

\begin{tabular}{|c|c|c|c|c|c|c|}
\hline Test insect & stage & peramine & Iolitrem & B ergopeptine & Ioline & effects \\
\hline \multirow[t]{2}{*}{ Argentine stem weevil } & adult & + & & $\mathrm{t}$ & $\mathrm{nt}$ & feeding deterrent \\
\hline & larvae & + & + & & + & $\begin{array}{l}\text { increased mortality, reduced growth } \\
\text { rates, feeding deterrent }\end{array}$ \\
\hline Black beetle & adult & & & + & nt & feeding deterrent \\
\hline Cutworm & larvae & + & $\mathrm{nt}$ & + & nt & $\begin{array}{l}\text { reduced growth rate, increased } \\
\text { mortality }\end{array}$ \\
\hline Grass grub & larvae & & & nt & + & $\begin{array}{l}\text { reduced growth rate, increased } \\
\text { mortality }\end{array}$ \\
\hline Porlna & larvae & & $\mathrm{nt}$ & nt & nt & \\
\hline
\end{tabular}

responsible for ryegrass staggers in grazing animals (Gallagher et al. 1981) and is both toxic and deterrent to Argentine stem weevil larvae (Table 2). Of the ergopeptines, ergovaline usually occurs in the highest concentration and has been linked to animal health problems, particularly in heat stressed environments (Fletcher 1993). This alkaloid affects black beetle feeding (Table 2). Peramine is commonly recognised as being responsible for adult Argentine stem weevil feeding deterrence (Rowan \& Gaynor 1986) and has no known effects on grazing animals. The lolines (NAcetyl and N-Formyl loline) have also been tested in some instances as these occur in high concentrations (e.g. $2000 \mathrm{ppm}$ ) in some fescues infected with Acremonium endophytes. They have been found to deter grass grub larval feeding but are not known to have any toxic affects on grazing animals.

In addition to those alkaloids listed in Table 2, several-minor-alkaloids,-which-are-possible-precursors to the major metabolites, have been tested for activity and many of these also have adverse effects against Argentine stem weevil (Prestidge \& Ball 1993). It is apparent from all these results that there is no one universal anti-insect metabolite in endophyte-infected ryegrass, and that much of the current endophytemediated resistance is due to different metabolites either acting together or affecting different insects. In one way, this may be extremely useful as it could reduce the opportunity for an insect to develop resistance to a

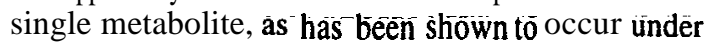
laboratory conditions (Pless et al. 1993).

\section{Effect of selected (non-commercial) Acremonium isolates on insect pests}

It is apparent that different alkaloids are responsible for effects on insects and on grazing animals. Since it is possible to artificially introduce Acremonium isolates into endophyte-free ryegrass and fescues (Festuca spp.) the development of an ideal endophyte/grass association now appears possible. There has been growing recognition that different Acremonium isolates have different alkaloid profiles, such that individual isolates may produce only some of the alkaloids and not others (Christensen et al. 1993). When these isolates are artificially introduced into a common host, such as Grasslands Nui, the same suite of alkaloids are usually produced as in the original host parent plant. This resource has become an extremely valuable research tool which has enabled demonstration of the effects of the major alkaloids within a common host plant cultivar on insects and grazing animals.

Using Nui as a common host plant cultivar, we have examined the effect of different isolates of Acremonium spp. obtained from a range of host plant material, for adverse effects against a number of pasture insect pests. As an example of the type of test conducted adult black beetle are confined to endophyte-infected and-endophyte-free-Nui-ryegrass ${ }^{-}$tillers $^{-}$planted-into soil in pots and left to feed for 10 days. Tillers are examined daily and assigned a feeding score depending on whether they are killed, damaged or healthy. An example of the results from such a feeding trial, which examined the extent of feeding on two selected isolates of Acremonium introduced into Nui ryegrass, compared with endophyte-free Nui ryegrass, is given in Figure 1. Further examples are provided by Ball et al. (1994). These types of feeding experiments have indicated that lolitrem B, peramine, paxilline and the loline alkaloids are not essential in endophyte-infected ryegrass to protect the host from adult black beetle feeding. Ergovaline may have a role in reducing feeding, but is not always present when deterrence is apparent. Thus other, as yet unknown, alkaloids may also be affecting black beetle.

Similar trials have been conducted on other important pastoral pests such as grass grub and porina. All of the endophyte/fescue combinations that have reduced grass grub larval survival and delayed growth in pot trials produced loline alkaloids but not all 
produced peramine or ergopeptines. Research on porina is not yet sufficiently advanced to state, with a degree of certainty, the alkaloid profile required in endophyte/ grass combinations to prevent porina caterpillar feeding densities.

\section{Is there an ideal endophyte?}

An ideal endophyte is likely to confer the selective advantage of protecting the plant against attacking insects, but without any adverse animal health effects. While this appears a simple goal, development and discovery of the ideal endophyte has proven to be difficult. It is obvious that different insect pests are affected by different metabolites produced by the endophyte/grass association (Table 2). For example, the ideal endophyte for Argentine stem weevil control will, at the minimum, contain peramine whereas endophytelgrass associations that only contain peramine will not be resistant to black beetle and grass grub. Results to date suggest that an ergopeptine alkaloid may be required to ensure ryegrass resistance from black beetle. Grass grub larvae and other root-feeding insect pests may require loline alkaloids to provide protection to the grasses. This may be overcome by producing a specific endophytelgrass combination which produces a narrow alkaloid profile for different regions of New Zealand where a particular pest is present, for example, black beetle in northern New Zealand. However, this is unlikely to be taken seriously by the forage seed industry considering the quantity of ryegrass seed required to be sold to make this commercially viable. Other problems may emerge with this approach as there is the possibility that narrowing the suite of metabolites that is currently found in commercially available endophyte-infected ryegrass cultivars will allow another, as yet unrecognised, insect that was being maintained at low densities by the existing combinations, to become a pest.

It is becoming increasingly apparent that, for most of New Zealand, an endophyte/grass combination which produces a cocktail of alkaloids at low stable concentrations may represent the ideal endophyte. The concentrations of endophyte mycelium and associated alkaloids within perennial ryegrass plants varies greatly among individual plants. Although there are large seasonal fluctuations within plants, the relative mycelium and alkaloid concentrations between plants with high and low levels are maintained (Figure 2). In addition, as the mycelium concentration within a plant increases, the alkaloid concentrations within the same plant also increases (Figure 3). The real challenge then is to determine the lower thresholds at which these alkaloids are required for pest control, and the upper
Figure 1 Mean feeding scores $(8=100 \%$ tillers killed, $0=100 \%$ tillers healthy) from adult black beetle choice feeding tests comparing endophyte-free Nui ryegrass (E-) and Nui infected with selected Acremonium isolates Lp5. and Tf13. Vertical bars = LSD 5\%.

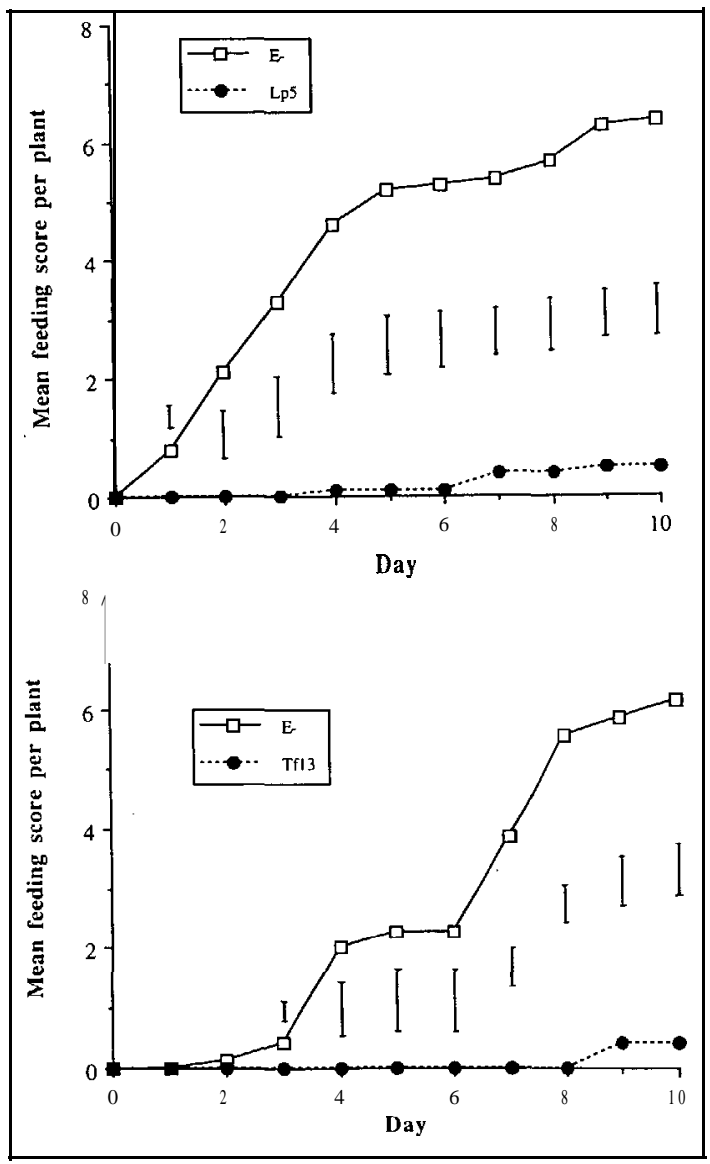

Figure 2 Monthly A. lolii mycelium concentrations during 1991 1992 from a high endophyte and low endophyte perennial ryegrass plant.

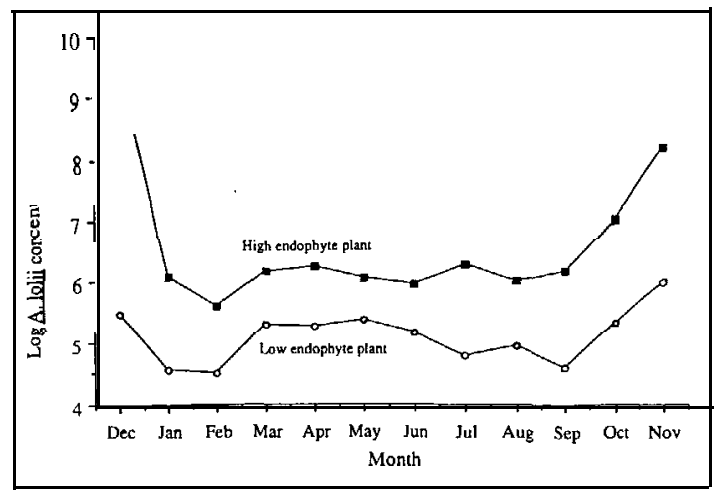


Figure 3 Relationship between the mean concentrations of A. lolii mycelium, and lolitrem $B$ and peramine in A. lolii-infected perennial ryegrass plants during 19911992.

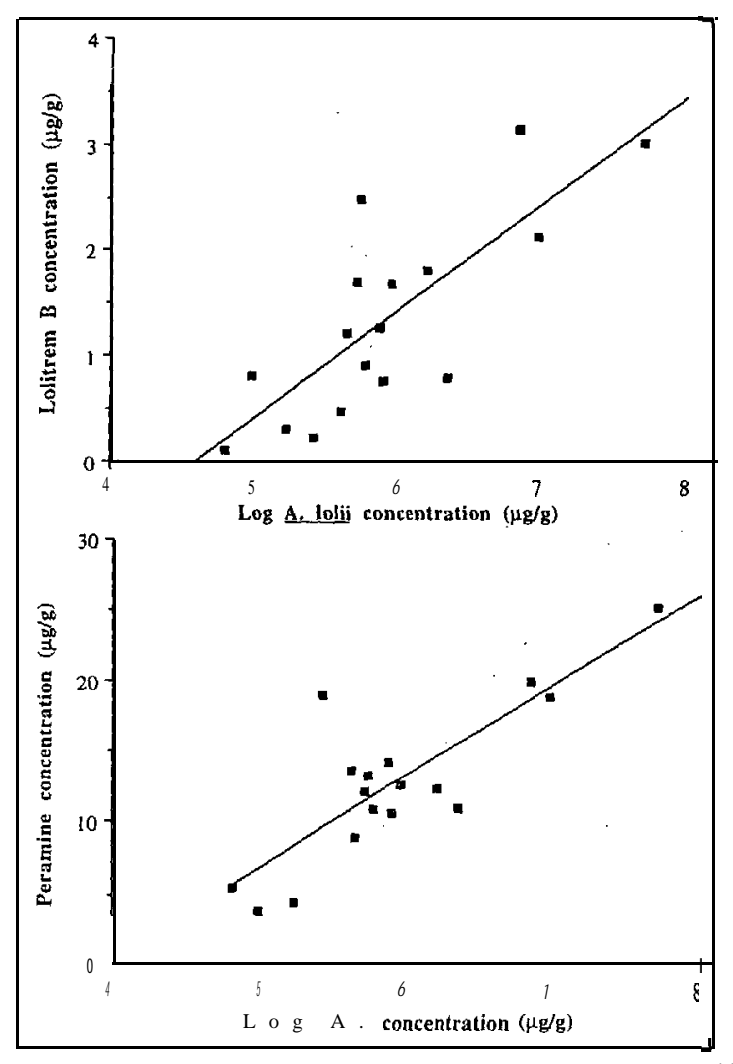

thresholds when animal health and productivity begin to be adversely affected.

\section{Summary}

Even with the commercial ryegrass cultivars currently available, Acremonium endophytes are acting as biological control agents against at least four pasture pests. The realisation that a single alkaloid-produced by the endophyte/grass association will not provide control against all of the major pasture pests, and the ongoing discoveries that different metabolites affect insect species and grazing animals in different ways, has made the target of an ideal endophyte more difficult to achieve. It is becoming increasingly apparent that a cocktail of metabolites at concentrations which maintain insect resistance, but do not cause animal health problems within an endophyte/grass combination, may be required to control many pasture pests in New Zealand. There is the added threat that release of selected endophyte/grass combinations with a narrow specific alkaloid profile may create further, as yet unrecognised, insect problems.

\section{ACKNOWLEDGEMENTS}

Our research has benefited greatly from interaction with the multidisciplinary team researching endophyte/ grass interactions. Technical support for the results presented was provided by Sergio Marshall, Robyn Mainland and Jane Entwisle.

\section{REFERENCES}

Ball, O.J-P.; Prestidge, R.A. 1992. The effect of the endophytic fungus Acremonium lolii on adult black beetle (Heteronychus arator) feeding. Proceedings of the New Zealand Plant Protection Society Conference 45: 201-204.

Ball, O.J-P.; Christensen, M.J.; Prestidge, R.A. 1994. Effect of selected isolates of Acremonium endophytes on adult black beetle (Heteronychus arator) feeding. Proceedings of the New Zealand Plant Protection Society Conference 47: in press.

Barker, GM.; Pottinger, R.P.; Addison, P.J. 1984a. Effect of Lolium endophyte fungus infections on survival of larval Argentine stem weevil. New Zealand journal of agricultural research 27: 279281.

Barker, G.M.; Pottinger, R.P.; Addison, P.J.; Prestidge, R.A. 1984b. Effect of Acremonium endophyte --fungus-infections-on behaviour of adult Argentine stem weevil. New Zealand journal of agricultural research 27: 271-277.

Barker, G.M.; Prestidge, R.A.; Pottinger, R.P. 1989. Role of Acremonium lolii in the population ecology of Listronotus bonariensis in New Zealand ryegrass pastures. p7-11. In: S. Quisenberry and R. Joost (Eds). Proceedings of the 1st International Symposium on Acremonium/Grass Interactions.

Christensen, M.J.; Latch, G.C.M.; Tapper, B.A. 1993. Taxonomy of Acremonium endophytes of tall-fescue (Fêstuca arundinacea), meadow fescue ( $F$. pratensis) and perennial ryegrasses. Mycological research 95: 918-923

Dymock, J.J.; Rowan, D.D.; McGee, I.R. 1989. Effects of endophyte-produced mycotoxins on Argentine stem weevil and the cutworm, Graphania mutans. Proceedings of the 5th Australasian Conference on Grassland Invertebrate Ecology: 35-43.

Fletcher, L.S. 1993. Grazing ryegrass/endophyte associations and their effect on animal health and performance. p115-120. In: D.E. Hume, G.C.M. Latch, H.S. Easton (Eds). Proceedings of the 2nd 
International Symposium on Acremonium/Grass Interactions: Plenary Papers. AgResearch, Grasslands Research Centre, Palmerston North, New Zealand.

Funk, CR.; Halisky, P.M.; Johnson, M.C.; Siegel, M.R.; Stewart, A.V.; Ahmad, S.; Hurley, R.H.; Harvey, J.C. 1983. An endophytic fungus and resistance to sod webworms: Association in Lolium perenne L. Bio/Technology I: 189-191.

Gallagher, R.T.; White, E.P.; Mortimer, P.H. 1981. Ryegrass staggers: Isolation of potent neurotoxins lolitrem A and lolitrem B from staggeis-producing pastures. New Zealand Veterinary Journal 29: 189. 190.

Goldson, S.L.; Phillips, C.B. 1993. Science and biological control. p347-354. In: R.A. Prestidge (ed). Proceedings of the 6th Australasian Conference on Grassland Invertebrate Ecology, AgResearch, Ruakura Agricultural Research Centre, Hamilton, New Zealand.

Hume. D.E.; Latch, G.C.M.; Easton, H.S. 1993. Proceedings of the 2nd International Symposium on Acremonium/Grass Interactions: Plenary Papers. AgResearch, Grasslands Research Centre, Palmerston North, New Zealand. 208pp.

Pearson, W.D. 1989. The pasture mealybug, Balanococcus poa'e (Maskell), in Canterbury: A preliminary report. Proceedings of the $5 t h$ Australasian Conference on Grassland Invertebrate E cology: 297-303.

Pless, C.R.; Gwinn, K.D.; Cole, A.M.; Chalkley, D.B.; Gibson, V.C. 1993. Development of resistance by Drosphila melanogaster (Diptera: Drosphilidae) to toxic factors in powdered Acremonium-infected tall fescue seed. pp. 170-174. In: D.E. Hume, G.C.M. Latch, H.S. Easton (Eds). Proceedings of the 2nd International Symposium on Acremonium/Grass Interactions. AgResearch, Grasslands Research Centre, Palmerston North, New Zealand.

Popay, A.J.; Mainland, R.A.; Saunders, C.J. 1993. The effects of endophytes in Fescue grass on growth and survival of third instar grass grub larvae. p174177. In: D.E. Hume, G.C.M. Latch, H.S. Easton
(Eds). Proceedings of the 2nd International Symposium on Acremonium/Grass Interactions, AgResearch, Grasslands Research Centre, Palmerston North, New Zealand.

Pownell, D.B.; Lucas, R.J.; Familton, A.S.; Love, B.G.; Fletcher, L.S. 1993. Endophyte associated mycotoxins and diarrhoea in lambs. pp. 132-134. In: D.E. Hume, G.C.M. Latch, H.S. Easton (Eds). Proceedings of the 2nd International Symposium on Acremonium/Grass Interactions. AgResearch, Grasslands Research Centre, Palmerston North, New Zealand.

Prestidge, R.A.; Ball, O.J-P. 1993. The role of endophytes in alleviating plant biotic stress in New Zealand. p141-151. In: D.E. Hume, G.C.M. Latch, H.S. Easton (Eds). Proceedings of the 2nd International Symposium on Acremonium/Grass Interactions: Plenary Papers, AgResearch, Grasslands Research Centre, Palmerston North, New Zealand.

Prestidge, R.A.; Pottinger, R.P.; Barker, G.M. 1982. An association of Lolium endophyte with ryegrass resistance to Argentine stem weevil. Proceedings of the New Zealand Weed and Pest Control Conference 35: 119-1 22.

Prestidge, R.A.; Gallagher, R.T. 1988. Endophyte fungus confers resistance to ryegrass: Argentine stem weevil larval studies. Ecological entomology 13: $429-435$.

Prestidge, R.A.; Watson, R.N.; Thorn, E.R. 1993. Invertebrate pests of endophyte-infected and endophyte-free perennial ryegrass swards in northern New Zealand. Proceedings of the XVII International Grassland Congress: 932-934.

Rowan, D.D.; Gaynor, D.L. 1986. Isolation of feeding deterrents against Argentine stem weevil from ryegrass infected with the endophyte Acremonium Ioliae. Journal of chemical ecology 12: 647-658.

Van Heeswijwk, R.; McDonald, G. 1992. Acremonium endophytes in perennial ryegrass and other pasture grasses in Australia and New Zealand. Australian journal of agricultural research 43: 1608-1 709. 